\begin{tabular}{|l|l|}
\hline La persistencia del pasado (1965) & Titulo \\
\hline Fernandes, Florestan - Autor/a & Autor(es) \\
\hline $\begin{array}{l}\text { Dominación y desigualdad. El dilema social latinoamericano. Florestan Fernandes. } \\
\text { Antología }\end{array}$ & En: \\
\hline Buenos Aires y Bogotá & Lugar \\
\hline $\begin{array}{l}\text { CLACSO, Consejo Latinoamericano de Ciencias Sociales } \\
\text { Siglo del Hombre Editores }\end{array}$ & Editorial/Editor \\
\hline 2008 & Fecha \\
\hline $\begin{array}{l}\text { Desigualdad racial; Estructura social; Poder; Distribución del ingreso; Discriminación } \\
\text { racial; Negros; Mulatos; Relaciones raciales; Ocupaciones; Esclavitud; } \\
\text { Modernización; Movimientos sociales; San Pablo; Brasil; }\end{array}$ & Temas \\
\hline Capítulo de Libro & Toleción \\
\hline http://bibliotecavirtual.clacso.org.ar/clacso/se/20100830104310/05flores.pdf & URL \\
\hline $\begin{array}{l}\text { Reconocimiento-No comercial-Sin obras derivadas 2.0 Genérica } \\
\text { http://creativecommons.org/licenses/by-nc-nd/2.0/deed.es }\end{array}$ & Licencia \\
\hline
\end{tabular}

Segui buscando en la Red de Bibliotecas Virtuales de CLACSO http://biblioteca.clacso.edu.ar

Consejo Latinoamericano de Ciencias Sociales (CLACSO)

Conselho Latino-americano de Ciências Sociais (CLACSO)

Latin American Council of Social Sciences (CLACSO)

www.clacso.edu.ar

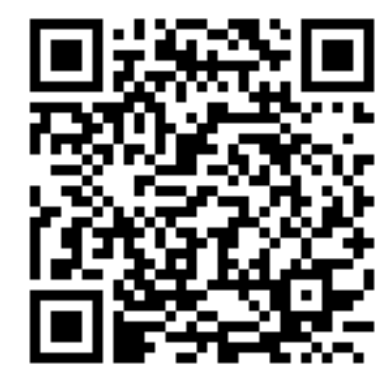


Fernandes, Florestan. La persistencia del pasado. En: Fernandes, Florestan. Dominación y desigualdad. El dilema social Latinoamericano : Florestan Fernandes. Antología / Florestan Fernandes; Heloísa Fernandes, compiladora. -- Bogotá : Siglo del Hombre, CLACSO, 2008. -- ISBN 978-958-665-114-1

Disponible en: http://bibliotecavirtual.clacso.org.ar/ar/libros/secret/critico/florestan/05flores.pdf 


\section{LA PERSISTENCIA DEL PASADO ${ }^{1}$}

\section{INTRODUCCIÓN}

En la situación de contacto racial imperante en Brasil, se ponen de manifiesto muchos problemas sociológicos de gran significación humana y científica. Brasil vive, simultáneamente, en varias “edades histórico-sociales". Según la región que se considere y el grado de desarrollo de las comunidades de la misma, podemos focalizar escenas que recuerdan los contactos de los colonizadores y de los conquistadores con los indígenas o bien registrar cuadros que retratan el surgimiento tumultuoso de la "civilización industrial”, con sus figuras típicas, nacionales o adventicias. Presente, pasado y futuro se entrecruzan y se confunden de tal manera que se puede pasar de un período histórico a otro a través del medio más simple: el desplazamiento en el espacio.

1 Este trabajo fue presentado originalmente en la Conference on Race and Color organizada por The American Academy of Arts and Science y The Congress for Cultural Freedom y realizada en Copenhague los días 6 a 11 de septiembre de 1965. Del mismo, los organizadores de la conferencia en inglés y francés realizaron una publicación previa, y posteriormente una publicación definitiva en el libro a cargo de John Hope Franklin titulado Color and Race (Boston, Houghton Mifflin Company, 1968, pp. 282-301). Texto extraído, para la presente edición, de Florestan Fernandes, O negro no mundo dos brancos, presentación de Lilia M. Schwarcz, São Paulo, Global Editora, 2007, pp. 104-130. 
Ahora bien, a cada período histórico le corresponde una situación humana. El observador ingenuo piensa que está en un mundo culturalmente homogéneo. Y de hecho, ciertos polarizadores impregnan las situaciones más contrastantes de un sustrato psicosocial y sociocultural común. Pero en realidad cada situación humana se organiza, estructural y dinámicamente, como un mundo material y moral con sus propias características. Sin duda, las diversas situaciones humanas posibles ponen a la luz, en su conjunto, los diferentes patrones de integración sociocultural de la sociedad brasileña, a lo largo de su formación y de su evolución en el tiempo y en el espacio. Pero cada una de ellas, de por sí, sólo puede ser comprendida y explicada por el propio patrón de integración sociocultural y por el modo en que se vincula con las tendencias involucradas de modernización de dicha sociedad.

Proyectadas contra ese telón de fondo, las relaciones étnicas y raciales y el significado del color en la vida humana se presentan bajo diversas facetas. Para debatir en este trabajo, elegimos el ejemplo que nos parece más indicado para una caracterización sucinta de lo que se podría entender como el dilema racial brasileño. Se trata de la situación del negro y del mulato en la ciudad de São Paulo. Esta ciudad no se distingue por la alta proporción de negros o de mestizos procedentes de negros y blancos en la población global. Por el contrario, bajo este aspecto São Paulo es una de las comunidades urbanas brasileñas en las que esa proporción es relativamente baja. La ciudad es significativa por otros motivos. Por un lado, porque se incluye en la última región de Brasil, en donde la esclavitud desempeñó funciones constructivas, como medio y punto de partida de un largo ciclo de prosperidad económica que se inició con la producción y la exportación de café. Por otro lado, porque fue la primera ciudad brasileña que expuso al negro y al mulato a las contingencias típicas e inexorables de una economía competitiva en expansión. En consecuencia, permite analizar, con objetividad y en condiciones casi ideales, cómo y por qué el antiguo orden racial no desapareció con la Abolicion y la finalización legal del régimen de castas, sino que se ha prolonga- 
do en el presente y se ha ramificado por las estructuras sociales creadas gracias a la universalización del trabajo libre.

\section{DESIGUALDAD RACIAL Y ESTRATIFICACIÓN SOCIAL}

El dilema racial brasileño, en la forma en que se manifiesta en la ciudad de São Paulo, echa sus raíces en fenómenos de estratificación social. Considerando la estructura social de la comunidad como un todo, se puede afirmar que, desde el último cuarto del siglo XIX hasta la actualidad, las grandes transformaciones histórico-sociales no han producido los mismos réditos para todos los sectores de la población. De hecho, el conjunto de transformaciones que dio origen a la "revolución burguesa", fomentando la universalización, la consolidación y la expansión del orden social competitivo, sólo benefició, colectivamente, a los segmentos blancos de la población. Todo pasó, históricamente, como si hubieran existido dos mundos humanos continuos, pero estancos y con destinos opuestos. El mundo de los blancos se vio profundamente alterado por la crisis económica y por el desarrollo social vinculados a la producción y a la exportación del café, al principio, y a la urbanización acelerada y a la industrialización, a continuación. El mundo de los negros se mantuvo prácticamente al margen de dichos procesos socioeconómicos, como si hubiera estado dentro de los muros de la ciudad, pero sin participar colectivamente de su vida económica, social y política. Por lo tanto, la disgregación y la extinción del régimen servil no significaron, de inmediato y a corto plazo, la modificación de las posiciones relativas de las reservas raciales presentes en la estructura social de la comunidad. El sistema de castas fue abolido legalmente; sin embargo, en la práctica la población negra y mulata continuó reducida a una condición social análoga a la preexistente. En lugar de ser proyectada en masa en las clases sociales en formación y en diferenciación, se vio incorporada a la "plebe", como si debiera convertirse en un estrato social dependiente y tuviera que compartir una "situación de casta" disimulada. Por este motivo, la desigualdad racial se mantuvo inalterada, en los términos del 
orden racial inherente a la organización social desaparecida legalmente, y el patrón asimétrico de relación racial tradicionalista (que le otorgaba al "blanco" la supremacía casi total y empujaba al "negro" hacia la obediencia y la sumisión) encontró condiciones materiales y morales para preservarse en bloque.

Los factores principales de dicho proceso de demora sociocultural son bien conocidos. En una visión retrospectiva y sintética, los factores mencionados pueden ser agrupados en cuatro constelaciones histórico-sociales sucesivas (aunque interdependientes): a) las tendencias asumidas por la transformación global de la comunidad; b) el carácter sociopático de las motivaciones que orientaron la adaptación del "negro" a la vida en la ciudad y a la naturaleza anómica de las formas de asociación que pudieron desarrollar; c) la inocuidad de la reacción directa del negro y del mulato contra la "marginación de la gente negra"; d) la aparición tardía y débil de correcciones propiamente estructurales del patrón heredado de desigualdad racial.

En la primera constelación debemos considerar tres grupos de factores histórico-sociales. En primer lugar, la ciudad de São Paulo no repite el patrón tradicional de desarrollo geográfico y socioeconómico de otras ciudades brasileñas, que se expandieron bajo la égida de la explotación del trabajo esclavo. La inclusión de São Paulo en la órbita de la economía colonial brasileña (basada en la exportación de productos tropicales) tuvo lugar tardíamente. Recién con la producción de café en el "oeste paulista” y gracias a la intensificación progresiva de la exportación de ese producto, la ciudad estuvo en condiciones de dejar de ser un burgo rústico y de contar con fuentes regulares de prosperidad económica. Es por este motivo que sólo a partir del último cuarto del siglo XIX São Paulo comenzó a experimentar modificaciones que la convirtieron propiamente en ciudad, al estilo de otros conglomerados urbanos de la época. Tal factor es de gran importancia. Los centros urbanos provocaban determinadas necesidades especiales que ampliaban la división del trabajo social. En ellos surgían ocupaciones y servicios que agrandaban el área de actividad constructiva del esclavo y, principalmente, que no 
podían ser ejercidos ni por el esclavo ni por el hombre libre. De esta manera, el liberto disfrutaba de algunas oportunidades económicas que le permitían integrarse a la estructura ocupacional de las ciudades y que forzaban a los blancos a adquirir interés por su adiestramiento y aprovechamiento en tal área. Se puede corroborar de qué manera ese mecanismo se manifestaba en ciudades como Salvador, Recife o Rio de Janeiro, en donde la población negra, y sobre todo la mestiza, lograban la adquisición de un nicho relativamente ventajoso en la organización ecológica y económica de aquellas comunidades. La inclusión tardía de la ciudad de São Paulo al núcleo de la economía colonial brasileña representó una desventaja para la población negra y mestiza de esa ciudad, tanto la esclava como la liberta. Esto es así porque el inicio de la expansión económica coincidió con la concentración creciente de inmigrantes de origen europeo y con la crisis del propio régimen servil. Pocos negros y mulatos pudieron aprovechar las oportunidades con las que contarían si las circunstancias hubieran sido otras, y que les permitirían convertirse en artesanos, pequeños comerciantes, etc. Cuando la Abolición hizo eclosión, estaban distribuidos en las ocupaciones menos deseables y compensadoras, pues las mejores oportunidades habían sido monopolizadas y absorbidas por los inmigrantes.

En segundo lugar, el movimiento abolicionista y todo el proceso de disgregación del régimen servil asumieron, como tenía que suceder fatalmente, el carácter de una insurrección de los propios blancos contra el orden esclavista y señorial. Éste comprometía el desarrollo socioeconómico de las regiones prósperas del país y sofocaba la expansión del capitalismo. Aunque el abolicionismo adquiriera el tenor de un movimiento humanitario, su resorte revolucionario residía en los intereses y valores sociales perjudicados por la vigencia de la esclavitud. Por otro lado, los negros y los mulatos se insertaban en esa insurrección como "objeto" y mera "masa de maniobra". Ellos no pudieron proyectar en ésta sus anhelos o necesidades más directas y, con raras excepciones, quedaron relegados a los roles secundarios. Así, lo que se podría llamar una "conciencia abolicionista" era, antes bien, un patri- 
monio de los mismos blancos, que lideraban, organizaban y al mismo tiempo contenían la insurrección dentro de límites que le convenían a la "raza dominante". Ese cuadro general produjo dos efectos negativos o limitativos. En cuanto a los blancos, favoreció un proceso paradójico: en la fase aguda de las transformaciones, el liderazgo del proceso pasó a manos de los círculos más conservadores, empeñados en atender los intereses sociales, económicos y políticos de los grandes hacendados. Aunque se negaran a concederles a los hacendados cualquier tipo de indemnización por las pérdidas financieras resultantes de la Abolición, ignoraron por completo la necesidad de poner en práctica medidas que aseguraran un mínimo de protección al esclavo o al liberto y que concentraran todo el esfuerzo constructivo en una política que garantizara la rápida sustitución de la mano de obra esclava. Por tal motivo, al final del Imperio y al inicio de la República, el principal rasgo de la política gubernamental provenía del fomento de la inmigración por todos los medios viables. En cuanto al negro, con la Abolición el mismo perdió los vínculos humanitarios que lo ligaban a los blancos radicales o inconformistas y dejó de formar una conciencia social propia de la situación. Como fue más un tutelado que un agente del proceso revolucionario, no tenía una visión objetiva y autónoma de sus intereses y posibilidades. Convirtió la libertad en un fin en sí y para sí, sufriendo con la desposesión una auténtica expoliación - la última por la cual la esclavitud aún sería responsable. La "explosión de alegría” pronto tendría un sabor amargo; pero la dignidad del "hombre libre" parecía valer más que cualquier otra cosa e, inmediatamente, el "negro" pasó a dedicarse intensamente a su afán de usufructuar un don que, en el pasado, lo había excluido de la condición humana.

En tercer lugar, la "revolución burguesa" prácticamente expulsó al "negro" de la escena histórica. Ésta se desarrolló en torno de dos figuras: el hacendado de café, que vio cómo sus roles sociales y económicos se diferenciaban gracias al crecimiento económico provocado por los "negocios del café", y a la expansión urbana; y el inmigrante, que se apropiaba tenazmente de todas las oportunidades nuevas, al mismo tiempo que eliminaba al "negro" 
de las pocas posiciones compensadoras que había alcanzado dentro del ámbito de las artesanías y en algunas ramas del pequeño comercio. Por lo tanto, "el negro" no sólo permaneció al margen de esa revolución, sino que fue seleccionado negativamente y tuvo que contentarse con lo que, de ahí en adelante, sería conocido como "trabajo de negro": trabajos inciertos o brutos, tan penosos como mal remunerados. Como consecuencia de ello, se encontró en una extraña situación. Mientras la prosperidad favorecía a todas las demás capas de la población, el "negro" se vio en apuros hasta para mantener o conquistar las fuentes estables de ingresos más humildes y relegadas.

En cuanto a la segunda constelación, debemos tener en cuenta cinco grupos de factores más significativos. En primer lugar, el negro no había sido adiestrado previamente, ya sea como esclavo o como liberto, para asumir los roles socioeconómicos del trabajador libre. Por tal motivo, no contaba con el entrenamiento técnico, ni con la mentalidad, ni con la autodisciplina del asalariado. Al verse y sentirse libre, quería ser literalmente tratado como HOMBRE, es decir, como "alguien dueño de su propio destino". Tales disposiciones redundaron en inadaptaciones fatales para el negro y el mulato. Por un lado, los empleadores blancos se irritaron en extremo con las actitudes y los comportamientos de los ex esclavos. Éstos usaron la libertad de forma predatoria. Suponían que, si eran "libres", podían trabajar como, cuando y donde lo prefirieran. Tendían a alejarse de las responsabilidades del trabajo cuando disponían de recursos suficientes para mantenerse en la ociosidad temporaria; y, en particular, se mostraban muy recelosos frente a las amonestaciones, advertencias o reprimendas. Alegando que "eran libres" (o que "el tiempo de la esclavitud ya acabó"), pretendían una autonomía que fundamentalmente se daba de bruces con el régimen del trabajo asalariado. Esos desentendimientos, naturalmente, serían transitorios. Pero, como había una relativa abundancia de mano de obra, en virtud del volumen alcanzado por la inmigración, los empleadores actuaron de manera intolerante, demostrando una notable incomprensión frente al negro y al mulato. Les parecía que éstos evidenciaban 
una "falta de responsabilidad" y que los negros eran "inútiles" o "intratables", fuera del "yugo de la esclavitud". Por otro lado, el mismo negro colocó la libertad encima de todo, como si ésta fuera un valor intocable y absoluto. Por falta de una socialización previa, no sabía evaluar correctamente la naturaleza y los límites de las obligaciones derivadas del contrato de trabajo. Éste era visto como si perpetuara la esclavitud por otros medios y como si, al vender su fuerza de trabajo, el trabajador estuviera vendiendo, simultáneamente, su propia persona. De esta circunstancia resultó una inadaptación verdaderamente estructural, agravada por el hecho de que sus oportunidades de trabajo eran las peores y de que existían dos niveles de retribución, lo cual degradaba el salario del trabajador negro.

En segundo lugar, la abundancia de mano de obra más calificada, como producto de la inmigración intensiva, favoreció la rápida modificación de la mentalidad de los empleadores y sus propensiones, incluso con respecto a la selección de los trabajadores agrícolas. Antes, el negro era representado como el único agente de trabajo posible, por lo menos con relación a los servicios degradados por la esclavitud. Por tal motivo, había una relativa tolerancia ante sus deficiencias y una real preocupación por corregirlas, en la medida de lo posible. Cuando quedó claro que podía ser reemplazado, incluso con relativa facilidad en las regiones prósperas, y que su sustituto era "más inteligente", "más eficiente" y "más laborioso" (o "industrioso"), aquellas disposiciones desaparecieron. Por lo tanto, de un momento a otro, el negro se vio condenado como agente de trabajo, pasando de la categoría de agente privilegiado a la de agente rechazado, en un momento en el cual él mismo elevaba sus exigencias morales y se volvía intransigente. De manera casi automática quedó relegado a la periferia del sistema de producción, a las ocupaciones indeseables, mal retribuidas y socialmente degradadas.

En tercer lugar, la esclavitud despojó al negro de casi toda su herencia cultural y lo socializó tan sólo para ocupar roles sociales confinados, en los cuales se realizaba el desarrollo de la personalidad del esclavo y del liberto. Como consecuencia de ello, 
la Abolición lo proyectó a la esfera de los "hombres libres" sin dotarlo de recursos psicosociales e institucionales para adaptarse a su nueva posición en la sociedad. No conocía ni podía poner en práctica ninguna de las formas sociales de vida organizada de las que normalmente gozaban los blancos (incluso la familia y los tipos de cooperación o de solidaridad que ésta condicionaba socialmente). Para disfrutar de los derechos del Hombre Libre tenía que despojarse de su segunda naturaleza, constituida como esclavo o liberto, y absorber las técnicas sociales que formaban parte del "mundo de los blancos". Estableciéndose en la ciudad de São Paulo, en donde la urbanización rápida y el crecimiento industrial acelerado provocaron la expansión intensa del orden social competitivo, esa laguna de origen específicamente sociocultural se erigiría como una barrera infranqueable. La incapacidad de lidiar eficazmente (o de cualquier manera) con las referidas técnicas sociales impidió su adaptación a las condiciones de vida imperantes en la ciudad, colocando al negro al margen de la historia, como si le fuesen vedadas las oportunidades crecientes, ávidamente aprovechadas por los inmigrantes y por el trabajador blanco de extracción nacional.

En cuarto lugar, luego de la declaración de la Abolición, la población negra se convirtió en una población altamente móvil. Muchos componentes de esa población, más o menos adaptados a la vida en la ciudad, se trasladaron al interior del estado de São Paulo o hacia otras regiones del país (al nordeste y al norte, principalmente, que era de donde provenían). Al mismo tiempo, oleadas sucesivas de negros y mulatos se apiñaban como podían en los sótanos y en las casas de inquilinato de la capital. En su conjunto, las pérdidas fueron ampliamente compensadas por las ganancias, pero con una nítida concentración de personas rústicas en un ambiente que exigía ciertas cualidades intelectuales y morales, requeridas por el trabajo asalariado y por la competencia económica. De por sí inadaptada, esa población tenía que vivir de trabajos con salarios insuficientes y apiñada en alojamientos (los sótanos y las casas de inquilinato que los albergaban no eran otra cosa que eso) que no tenían capacidad para tantos habitantes. 
El único elemento de esa población que contaba con un empleo asalariado más o menos cierto era la mujer, que podía dedicarse a los servicios domésticos. De modo que fue ella la que, rápidamente, se convirtió en el sostén de las agrupaciones domésticas, ya que de ella provenía el sustento parcial o total de la casa, la ropa y la comida del marido o del concubino, e incluso el dinero con el que éstos enfrentaban sus pequeños gastos. El ocio del hombre, que en un comienzo era producto de la contingencia y constituía una protesta digna, pronto se transformó, en considerables proporciones, en una forma aprensiva y sociopática de explotación de un ser humano por otro. Además, tres cuartas partes de la población negra y mestiza de la ciudad se sumergieron en una dolorosa era de miseria colectiva, de degradación moral y de vida social desorganizada. El abandono del menor, del enfermo o del anciano, la "madre soltera", el alcoholismo, la vagancia, la prostitución, la criminalidad ocasional o sistemática, despuntaron como dimensiones normales de un drama humano sin precedentes en la historia social de Brasil. En esas condiciones, el negro no contaba con elementos para cultivar ilusiones sobre el presente o el futuro. Y, como si esto fuera poco, acumulaba puntos negativos, pues el blanco percibía y explicaba de manera etnocéntrica los aspectos de esa situación de la que tomaba conocimiento, a través de escenas deprimentes, o de los noticieros, adjudicándole al mismo negro la "culpa" por lo que ocurría (como si el negro "no tuviese ambiciones", "no le gustara trabajar", "fuera un alcohólico inveterado", "tuviera propensión al crimen y a la prostitución" y "no fuera capaz de manejar su propia vida sin la dirección y el yugo del blanco"). No obstante, el drama en sí mismo no conmovió a los blancos ni fue sometido al control social directo o indirecto; sólo sirvió para degradar aún más a su víctima con el consenso generalizado.

En quinto y último lugar, el negro y el mulato no disponían de técnicas sociales que les posibilitaran el control eficiente de sus dilemas y la superación rápida de esa fase de vida social anómica. Por su parte, las demás capas de la comunidad no revelaron ninguna especie de compasión o de solidaridad ante el drama 
material y moral del negro, mientras que la misma comunidad como un todo nada podía hacer, ya que no disponía de una red de servicios sociales suficientemente complejos para resolver problemas humanos tan graves. La miseria se asoció a la anomia social, formando una cadena de hierro que ataba al negro, colectivamente, a un destino inexorable. A la degradación material le correspondía la desmoralización: el negro se entregaba a ese destino sumido en una profunda frustración e insuperable apatía. Pronto se difundió y se arraigó un estado de espíritu derrotista, según el cual "el negro nació para sufrir", "la vida del negro es así", "no vale la pena hacer nada", etc. El único punto en el que el negro no cedía se relacionaba con su obstinada permanencia en la ciudad. Como si fuera un paria de la era moderna, aceptaba pasiva y conformadamente el peso de la desgracia y los días inciertos que el futuro le reservaba.

En la tercera constelación, debemos considerar las causas y los efectos de los movimientos sociales que se constituyeron en el medio negro de São Paulo. Ningún conglomerado humano podría soportar, de modo totalmente inerte, una situación como la que las poblaciones negra y mulata enfrentaron en esa ciudad. Poco a poco se fueron esbozando y fueron cobrando fuerza algunos tímidos intentos de crítica y de autodefensa. Entre 1925 y 1930, esos intentos tomaron cuerpo y produjeron sus primeros frutos maduros, expresados en una prensa negra empeñada en difundir formas de autoconciencia de la situación racial brasileña y del "abandono del negro", y también en organizaciones dispuestas a llevar la "protesta de la gente negra" al terreno práctico. Por primera vez en la historia social de la ciudad, negros y mulatos se unían para defender los intereses económicos, sociales y culturales de la "raza", buscando formas de solidaridad y de actuación social organizada que redundasen en beneficio de la reeducación del negro, en la elevación progresiva de su participación a nivel de los ingresos, en el estilo de vida y en las actividades políticas de la colectividad y, por consiguiente, de su capacidad de convertirse en ciudadano según los modelos impuestos por la sociedad inclusiva. Sin embargo, los movimientos sociales sólo lograron atraer 
a pequeños grupos de la población negra y mulata de la capital. Una vez malogrado su alcance constructivo, el conformismo, la apatía y la dependencia con relación a los blancos bloquearon ese camino de afirmación autónoma. Aunque llegaran a abarcar grupos de militantes tildados de alarmantes por los blancos, los movimientos no sirvieron más que para crear un marco histórico y redefinir las actitudes o los comportamientos de negros y mulatos. Desenmascarando la ideología racial dominante, ellos elaboraron una contraideología racial que aumentó el área de percepción y de conciencia de la realidad racial brasileña por parte del negro. Por otro lado, acentuando ciertas tendencias igualitarias fundamentales, llevaron al negro a enarbolar las banderas de la democracia racial, exigiendo para sí condiciones equitativas de participación en los niveles de ingresos, en el estilo de vida y en las prerrogativas sociales de las demás capas de la comunidad. Como las reivindicaciones hacían eclosión de forma pacífica, las mismas no engendraron disposiciones de segregación racial y no alimentaron tensiones o conflictos de carácter racial. En ese sentido, ellas fueron socialmente constructivas, difundiendo imágenes del negro, recalibrando su manera de resolver sus problemas y tratando de absorber las técnicas sociales y de aprovechar las oportunidades económicas de las que disfrutaban los blancos. Respondieron literalmente a las exigencias del orden social competitivo, afirmándose como el único proceso por el cual la población negra de la capital trató de adaptarse colectivamente a las exigencias histórico-sociales del presente. No obstante, tales movimientos, con los objetivos que tenían en vista, no repercutieron constructivamente entre los blancos. Éstos se mantuvieron indolentes frente a ellos, e irguieron un muro de indiferencia y de incomprensión que anuló su eficacia práctica, impidiendo que aquéllos hicieran su aporte, de hecho, para adaptar el sistema de relaciones raciales al orden social competitivo. Además de ello, los círculos más influyentes, imbuidos de actitudes y valoraciones tradicionalistas, reinterpretaron los movimientos sociales surgidos en el medio negro como un "peligro" y como una "amenaza" (como si éstos "introdujeran el problema racial en el país"). Algunos defendían el punto 
de vista de que si "la negrada se sintiera cómoda", después "nadie lograría contener a esa gente". En la época del Estado Novo, ${ }^{2}$ los movimientos fueron legalmente proscriptos y se clausuró el Frente Negro Brasileño, la principal organización aparecida en ese período. Con la extinción del Estado Novo, de 1945 a 1948, se esbozaron algunos intentos de reorganización de aquellos movimientos. Pero todos ellos fracasaron estrepitosamente, pues los negros y los mulatos en ascensión social prefirieron adoptar una estrategia estrechamente egoísta e individualista de "solución del problema del negro". En el fondo, la inexistencia de mecanismos de solidaridad racial privó al medio negro de sus cuadros humanos. Sin embargo, en un plano más general ello significa que la contribución que los movimientos sociales podrían otorgarle a la modernización del sistema tradicional de relaciones raciales quedó comprometida y neutralizada. La adaptación de aquel sistema a la situación histórico-social imperante en la ciudad depende, actualmente, y siempre y cuando no surjan modificaciones, de los efectos lentos e indirectos de la absorción gradual del negro y del mulato al orden social vigente.

En la cuarta constelación, debemos considerar cómo repercutió a corto plazo la expansión del orden social competitivo en la graduación de las oportunidades económicas otorgadas a los negros y mulatos. En el período inmediatamente posterior a la Abolición, las oportunidades fueron monopolizadas por los blancos de las antiguas capas dominantes y por los inmigrantes. Un sondeo estadístico, realizado en la ciudad en 1893, indica de modo bien claro esa tendencia. Así, de 170 capitalistas, 137 eran nacionales $(80,5 \%)$ y 33 , extranjeros $(19,4 \%)$. De 740 propietarios, 509 eran nacionales (69\%) y 231 extranjeros (31\%). En ciertas profesiones conspicuas, tradicionalmente controladas por las elites locales, el extranjero sólo aparecía esporádicamente. Ello sucedía, por ejemplo, con la magistratura y la abogacía. Pero en

2 Sistema de gobierno instaurado en Brasil por el presidente Getúlio Vargas a partir del año 1937, y que se mantuvo durante todo su gobierno, hasta su destitución en 1945. (N. del E.). 
profesiones más vinculadas con el progreso técnico, los extranjeros se destacaban en proporciones significativas. Es lo que se puede inferir, por ejemplo, de profesiones como la ingeniería (127 nacionales y 105 extranjeros), la arquitectura (23 nacionales y 34 extranjeros), la agrimensura (10 nacionales y 11 extranjeros), la docencia ( 274 nacionales y 129 extranjeros), etc. Entre el llamado "personal de las industrias", el inmigrante aparecía prácticamente como el agente privilegiado. Con excepción de las ocupaciones agrícolas, en las cuales el elemento nacional predominaba (pues presentaba 1.673 trabajadores nacionales, es decir, el 68\%, y 783 extranjeros, o sea, el 32\%), en las demás áreas, de hecho, urbanización equivalía a europeización. He aquí los ejemplos más relevantes: servicios domésticos, 5.878 nacionales $(41,6 \%)$ y 8.226 extranjeros $(58,3 \%)$; actividades manufactureras, 774 nacionales $(21 \%)$ y 2.893 extranjeros $(79 \%)$; trabajos de artesanos y artistas, 1.481 nacionales $(14,4 \%)$ y 8.760 extranjeros $(85,5 \%)$; actividades de transporte y conexos, 1.998 nacionales $(18,9 \%)$ y 8.527 extranjeros $(81 \%)$; actividades comerciales, 2.680 nacionales $(28,3 \%)$ y 6.776 extranjeros $(71,6 \%)$. Si se consideran todas estas actividades, en promedio el $71,2 \%$ de las ocupaciones se encontraban bajo el control de los extranjeros. Como, según otras informaciones dispersas, sabemos que la participación del negro en ese cuadro ocupacional, sobre todo en los trabajos calificados y semicalificados, era mínima, esto nos da una idea indirecta muy significativa. El desarrollo económico posterior de la ciudad corrigió esa situación, pero de manera casi insignificante. De hecho, sólo después de 1935, con la intensificación de las migraciones internas, el "hambre de brazos" aumentó acentuadamente las oportunidades ocupacionales de la población negra y mulata. Sin embargo, la modificación fue más cuantitativa que cualitativa. Un mayor número de personas de aquella población pasó a tener alguna facilidad en la obtención de fuentes estables de ingresos, aunque tal situación se continuó dando predominantemente en la esfera de los servicios menos calificados y peor remunerados. Un sondeo que hicimos en 1951 revela que el negro está encontrando, en nuestros días, el punto de partida del 
que podría haber disfrutado en el período de disgregación del régimen servil, si no se hubiera topado con la competencia del inmigrante. En la muestra estudiada, elegida fortuitamente entre hombres y mujeres, descubrimos que el $29 \%$ de los negros y mulatos se distribuían entre las ocupaciones artesanales y el 21\% se empleaban en los servicios domésticos. En cuanto a otras actividades, las siguientes indicaciones pueden dar una clara idea de la situación: en servicios públicos, como ordenanzas, auxiliares de limpieza y empleados administrativos, predominantemente, el 9\%; en la industria, una buena parte como encargados de servicios brutos o semicalificados, el $8 \%$; en oficinas, pocos dactilógrafos, redactores de cartas o tenedores de libros, el $7 \%$; en el comercio, y sólo algunos, como vendedores o jefes de sección, el $4 \%$, etc. En suma, el cuadro se ha modificado, pero muy poco. El negro aún se encuentra en una posición muy desventajosa en la pirámide ocupacional y tiene endebles posibilidades de corregir esa situación en un futuro próximo. A ese respecto también deberían tenerse en cuenta los datos del censo de 1940. Reuniendo sólo las indicaciones más significativas, podríamos elaborar el siguiente cuadro:

Distribución de los hombres y mujeres de 10 años y más, según la posición en algunas ocupaciones, Municipio de São Paulo (censo de 1940)

\begin{tabular}{|l|r|r|r|r|r|}
\hline \multicolumn{1}{|c|}{$\begin{array}{c}\text { Posición en la } \\
\text { ocupación }\end{array}$} & Blancos & Negros & Pardos & Amarillos & \multicolumn{1}{c|}{ Totales } \\
\hline Empleador & 15.261 & 51 & 72 & 342 & 15.726 \\
& $97,04 \%$ & $0,32 \%$ & $0,45 \%$ & $2,17 \%$ & $100 \%$ \\
\hline Empleado & 323.997 & 15.114 & 10.925 & 2.317 & 352.353 \\
& $91,95 \%$ & $4,28 \%$ & $3,1 \%$ & $0,65 \%$ & $100 \%$ \\
\hline Autónomo & 74.448 & 2.051 & 1.595 & 1.577 & 79.671 \\
& $93,44 \%$ & $2,57 \%$ & $2 \%$ & $1,98 \%$ & $100 \%$ \\
\hline Miembro de la & 4.644 & 80 & 56 & 565 & 5.345 \\
familia & $86,88 \%$ & $1,5 \%$ & $1,04 \%$ & $10,57 \%$ & $100 \%$ \\
\hline Posición ignorada & 4.393 & 356 & 325 & 44 & 5.118 \\
\hline Participación en la & 1.203 .111 & 63.546 & 45.136 & 14.074 & $1.326 .621 *$ \\
población & $90,72 \%$ & $4,79 \%$ & $3,4 \%$ & $1,06 \%$ & $100 \%$ \\
\hline
\end{tabular}

* Incluyendo 394 individuos de color no declarado. 
A pesar del carácter pesimista de las conclusiones que tales datos ofrecen, en su conjunto, las modificaciones resultantes tienen una gran significación. La adquisición de fuentes estables de ingresos, sin importar en qué condiciones, les ofreció al negro y al mulato medios de integración de la estructura ocupacional y, en consecuencia, una situación favorable a la absorción gradual de las técnicas sociales anteriormente monopolizadas por el blanco. Por otro lado, al mismo tiempo alcanzaron un nivel de clasificación ocupacional y de competencia con el blanco que les abren algunos canales de movilidad social vertical a las poblaciones negra y mestiza. No sólo los negros y los mulatos pueden "pertenecer al sistema", sino que ellos también pueden "luchar para subir", es decir, para "mejorar su posición dentro del sistema". Aunque sean raras y débiles, las "elites de color" o las "clases medias de color" aparecen como una realidad nueva y tendrán oportunidades de aumentar continuamente, en tanto y en cuanto se mantengan las actuales condiciones socioeconómicas.

Las cuatro constelaciones de factores actúan en la misma dirección y producen efectos sociodinámicos de la misma naturaleza. Éstos mantienen la desigualdad racial en niveles y de acuerdo con un patrón sociocultural extraño al orden social competitivo y a una sociedad multirracial democrática. Como si el pasado se reprodujera constantemente en el presente, la concentración racial del ingreso, del prestigio social y del poder engendra un andamiaje social que nada (o muy poco) ostenta de competitivo, de igualitario y de democrático en sus líneas raciales. Los blancos disfrutan de una hegemonía completa y total, como si el orden social vigente fuera, literalmente, una combinación híbrida del régimen de castas y del régimen de clase. En lo que se refiere a la integración del blanco al sistema de relaciones sociales, sólo el último régimen tiene plena vigencia. Pero, cuando se trata del negro o del mulato, ambos regímenes se combinan de formas variables, siempre haciendo que ciertas influencias arcaicas operen libremente, revitalizando de modo extenso y profundo un orden racial que ya debería ser una reliquia histórica. 


\section{PREJUICIO Y DISCRIMINACIÓN EN LAS RELACIONES RACIALES}

Este telón de fondo puede pasar por un "fenómeno natural". Sin embargo, sucede que el mismo favorece la perpetuación y, en ciertos aspectos, la revitalización del estándar tradicionalista y asimétrico de relaciones raciales. Dicho estándar se mantuvo, por así decir, intacto hasta 1930, aproximadamente, es decir, medio siglo después de la Abolición. Y, aún en la actualidad, no se podría decir que haya entrado en una crisis irreversible o que esté en vías de ser superado. Éste se preserva parcialmente, aunque encuentra refuerzos continuos en la extrema desigualdad de la situación económica y del destino social de las dos reservas "raciales" presentes. La alternativa de la desaparición final de este estándar de relación racial sólo se concretará históricamente en el momento en que la población negra y mestiza de la ciudad logre alcanzar, en bloque, situaciones de clase equivalentes a las que son disfrutadas por la población blanca. Esto es lo mismo que admitir que ello sucederá cuando el orden social competitivo esté despojado de las inconsistencias económicas, sociales y culturales a las que se tiende en torno de las tendencias de concentración racial del ingreso, del prestigio social y del poder.

En términos generales, el quid del "dilema racial brasileño" - tal como el mismo puede ser caracterizado sociológicamente a través de una situación histórico-social de contacto como la que predomina en la ciudad de São Paulo_ - reside antes en el desequilibrio existente entre la estratificación racial y el orden social vigente que en influencias etnocéntricas específicas e irreductibles. Sin embargo, el estándar de relación racial tradicionalista contenía influencias sociodinámicas etnocéntricas. Y éstas no han desaparecido, sino que continúan fuertes y activas gracias al andamiaje social que preserva una concentración racial del ingreso, del prestigio social y del poder, más representativo de una "sociedad de castas" que de una "sociedad de clases".

Para los fines de esta exposición, bastaría considerar algunos aspectos cruciales de esa compleja situación. El prejuicio y 
la discriminación surgieron en la sociedad brasileña como una contingencia ineluctable de la esclavitud. Los principios católicos proscribían la esclavitud del hombre por el hombre. Además, le imponían al señor, como obligación fundamental, el deber de llevar su fe y asegurar la salvación del esclavo, lo que los igualaría ante Dios. Para evadirse de tales obligaciones o volverlas inocuas apelaron a un proceso aberrante de racionalización sociocultural que convirtió la propia esclavitud en una relación aparentemente piadosa y misericordiosa. El esclavo sería un bruto, un ser entre las fronteras del paganismo y de la animalidad, cuya existencia y supervivencia resultaban de una responsabilidad asumida generosamente por el señor. Por consiguiente, a la condición de esclavo le correspondería una degradación total, que afectaría por completo su naturaleza biológica y psicológica. Como criatura "subhumana", aparecía como "inferior" y "dependiente", imponiéndose correlativamente la condición social de señor como una carga material y moral. Tales racionalizaciones, penosamente requeridas por los principios religiosos, eran duramente reforzadas por instituciones tomadas del derecho romano, que excluían al esclavo de la condición de persona y le otorgaban al señor un poder casi ilimitado. En esa conexión de sentido, el prejuicio contra el negro y su descendiente mestizo (pues la condición de cosa era transmitida por la madre: partus sequiturventrem) se configuraba, socialmente, como una entidad moral. En ese contexto, las marcas raciales desempeñaban un papel secundario o adjetivo, porque éstas apenas servían para señalar ostensivamente, como si fueran un estigma, a los portadores de la condición degradante e infamante de esclavo y, más tarde, de liberto. Por lo tanto, en el fondo el prejuicio, que se convertía en racial por una contingencia de los orígenes biológicos de los esclavos, cumplía una función racionalizadora. Le correspondía legitimar lo que era socialmente ilegitimable. Gracias a él, el señor podía lidiar libremente con los principios de su cultura y justificarse moralmente, frente a su conciencia religiosa y al consenso general.

Por su parte, la discriminación emergía y se objetivaba socialmente como requisito institucional de la relación señor-esclavo y 
del orden social correspondiente. Como el fundamento de la distinción entre el señor y el esclavo procedía de su condición social (y, por tal motivo, de su posición recíproca), la discriminación se elaboró, primariamente, como un recurso para distanciar socialmente categorías raciales coexistentes y como un medio para revitalizar las relaciones o la convivencia entre el señor y el esclavo. Palabras, gestos, ropas, alojamiento, alimentación, ocupaciones, recreación, acciones, aspiraciones, derechos y deberes, todo cayó dentro del ámbito de este proceso, que proyectó la convivencia y la coexistencia en una separación extrema, rígida e irremediable de dos categorías sociales que eran, al mismo tiempo, dos reservas raciales. Así mismo, los esclavos formaban la masa de la población, una mayoría potencialmente peligrosa y, si pudiese explotar, incontrolable. De esta manera, se los percibía y representaba como "enemigos del orden" público y privado. Para mantenerlos bajo el yugo señorial y en la condición de esclavos, se agregaba la violencia como medio normal de represión, de disciplina y de control. En ese amplio marco, no sólo las dimensiones humanas del esclavo como "persona" fueron ignoradas: también se afirmó el hábito inflexible de ponerlo y de mantenerlo en su lugar, de forzarlo violenta o blandamente a la obediencia y a la pasividad. En suma, se diferenciaron dos mundos sociales distintos y opuestos, entre dos reservas raciales que participaban de culturas diferentes y que tenían destinos sociales antagónicos. Esos puntos deben ser retenidos claramente si se quiere entender la situación de contacto racial imperante en Brasil. Las fuentes de distinción y de separación no eran primariamente raciales. Pero se convertían en tales en la medida en que detrás del señor estaba el "blanco", y detrás del esclavo se ocultaba el "negro" o el "mestizo".

Es importantísimo mencionar estos hechos. Por un lado, porque ellos esclarecen los orígenes sociales remotos del prejuicio y de la discriminación raciales en Brasil; por otro, porque delimitan las funciones sociales que cumplían el prejuicio y la discriminación raciales en la sociedad brasileña del pasado. Uno servía para legitimar comportamientos e instituciones moralmente proscritos. La otra, para regular la convivencia interracial, sometiendo 
todas sus manifestaciones, incluso las más íntimas, a un código ético verdaderamente inflexible en la preservación de la distancia económica, social y cultural existente entre el señor y el esclavo. Ello sugiere que, desde sus orígenes más lejanos, el prejuicio y la discriminación tienen dos facetas. Una, evidente, es estructural y dinámicamente social. El señor y el esclavo se relacionan y se oponen como categorías sociales. Tanto el prejuicio como la discriminación se vinculan, fundamentalmente, con la estructura y el funcionamiento de una sociedad de castas, en la cual la estratificación racial responde a los principios de integración económica y sociocultural de la organización social. Otra, menos aparente y más disimulada, es de cuño racial. Los señores pertenecían a las reservas raciales blancas y, en nombre de sus intereses y valores sociales, ejercían una dominación social. Lo mismo ocurría con los esclavos, seleccionados entre las reservas raciales negra o mestiza, sin intereses sociales autónomos y sujetos a una dominación social que era, al mismo tiempo, una dominación racial.

La estratificación social presuponía, pues, una estratificación racial, y la ocultaba. Como una era inherente a la otra, se puede admitir la existencia de un paralelismo fundamental entre "color" y "posición social”. En el límite histórico extremo, provisto por el orden social esclavista y señorial, los principios raciales como que se diluían y desaparecían por detrás de los principios sociales de integración del orden social. Pero el análisis puede deshacer esa apariencia, evidenciando ambas facetas de la correlación entre "estructura social" y "estructura racial" de la sociedad. Por otro lado, en otras polarizaciones, ese paralelismo deja de ser tan completo y las cosas salen a la luz por sí mismas. La importancia de la ciudad de São Paulo, como caso crucial para el estudio del tema, consiste en que permite observar las diversas polarizaciones sucesivas de aquel paralelismo, desde la disgregación final del antiguo régimen hasta la formación de la sociedad de clases.

Dejándose a un lado la era de la esclavitud, lo cual no nos interesa de inmediato en esta discusión, tenemos frente a nosotros tres problemas significativos. El primero se refiere a la etapa de transición, en la que el patrón tradicionalista y asimétrico de rela- 
ción racial subsiste inalterable. El segundo atañe a lo que sucede cuando la ascensión social del negro provoca alguna especie de ruptura en el paralelismo entre "color" y "posición social". El tercero se relaciona con la existencia o inexistencia de probabilidades de incorporación del mencionado paralelismo al régimen de clases sociales, lo cual redundaría en la absorción de la desigualdad racial por el orden social competitivo en expansión.

El primer problema puede ser ilustrado con lo que ocurrió en São Paulo entre 1888, fecha de la Abolición, y 1930, aproximadamente. En las condiciones señaladas anteriormente, de exclusión casi completa de la vida económica activa, de desorganización social y de apatía, la población negra y mestiza prácticamente permaneció en un estatus equivalente al del liberto en el orden social esclavista y señorial. El estándar tradicionalista y asimétrico de relación racial fue transferido en su casi totalidad a la nueva situación histórico-social, como si la modificación del estatuto jurídico del negro y del mulato no se reflejara en sus prerrogativas sociales. Por su parte, ellos se acomodaban pasivamente a las actitudes y a los comportamientos prejuzgantes o discriminatorios del blanco, llegando, incluso, a desorientarse cuando éste actuaba de forma diversa (digamos: "igualitaria" o "democrática"). Al mismo tiempo, los blancos, principalmente los de los estratos altos o en ascensión social, toleraban muy mal otro tipo de reacción del negro y del mulato. Revelaban una notable incomprensión y una extrema intransigencia ante aquellos que "se salían de la línea", pretendiendo tratar a los blancos como si "fueran gente de su misma calaña”. Por lo tanto, no sólo el estándar tradicionalista de relación racial se mantenía en vigencia: toda la estructura social que lo soportaba, la ideología racial que le daba sentido y las funciones sociales que el mismo cumplía se preservaban con plena vitalidad en el plano de las acomodaciones raciales.

Esos hechos son verdaderamente significativos desde el punto de vista sociológico. Los mismos indican dos cosas esenciales. En primer lugar, que las innovaciones que afectan al patrón de integración del orden social no por ello repercuten de modo directo, inmediato y profundo en la ordenación de las relaciones 
raciales. Allí en donde persiste el mundo tradicionalista brasileño, es inevitable que sobreviva, más o menos fuerte, el paralelismo entre "color" y "posición social", aunque los agentes humanos involucrados nieguen esa realidad. En segundo lugar, el prejuicio y la discriminación raciales no emergen como subproductos históricos de la modificación legal del estatus social del negro y del mulato. Por el contrario, la persistencia de ambos constituye un fenómeno de demora cultural: actitudes, comportamientos y valores del régimen social anterior son transferidos y mantenidos, en la esfera de las relaciones raciales, en situaciones históricosociales en las que entran en conflicto abierto con los fundamentos económicos, jurídicos y morales del orden social vigente. Es necesario hacer notar, en este pasaje, que las manifestaciones de prejuicio y de discriminación raciales nada tienen que ver con amenazas tal vez creadas por la competencia o por la rivalidad del negro con el blanco, ni con el agravamiento real o potencial de las tensiones raciales. Éstas son expresiones puras y simples de mecanismos que mantuvieron, literalmente, el pasado en el presente, preservando la desigualdad racial al estilo de la que imperaba en el régimen de castas. Ello significa, naturalmente, que en donde el tradicionalismo se perpetúa incólume, en la esfera de las relaciones raciales — por más que se sostenga lo contrario-, el mismo acarrea la supervivencia tácita del paralelismo entre "color" y "posición social".

El segundo problema merece mayor atención. En determinadas circunstancias, el negro o el mulato podían salirse de su propia piel en el orden social esclavista y señorial. La condición era que se incorporaran al núcleo de la familia blanca de bien o que fueran aceptados como sus elegidos, apadrinados, protegidos, etc. En ese caso, el individuo en cierta medida perdía parcialmente su identidad racial y adquiría, también parcialmente, la identidad social de la familia a la que pasaba a deber su lealtad. No se puede afirmar, como piensan muchos, que semejante alternativa acarrease una corrección completa y definitiva del "color" por la "posición social". Según parece, se ampliaba, algunas veces considerablemente, el ámbito de aceptación y de actuación so- 
cial de la "persona de color" en el medio blanco. Sin embargo, para muchos efectos, el individuo debía saber guardar las apariencias, manteniéndose "en su lugar" cuando fuera necesario y desarrollando una verdadera política de seducción sistemática de los ánimos de aquellos blancos ante los cuales debía transigir incondicionalmente. Aquí nos encontramos ante un tipo de ascensión social que se podría llamar infiltración socialpropiamente dicha. A través de la misma, se abría una válvula de movilidad vertical que, al premiar al "mulato de talento" o al "negro notable", producía una continua e inexorable acefalización en el seno de la "población de color". No obstante, tal mecanismo, además de abarcar números reducidos de personalidades, en nada contribuía a modificar la situación racial o la imagen del negro hecha por el blanco. Los personajes, seleccionados por sus dotes singulares, funcionaban como "la excepción" que confirma la regla. Lo que ellos hicieran de excepcional no beneficiaba a su "raza": era considerado algo que denotaba la influencia o la herencia psicobiológica y social del blanco. Respecto a ellos se decía: "negro de alma blanca", "negro sólo por fuera", "es blanco por dentro", "ni parece negro", etc. Simultáneamente, si no cumplían con alguna expectativa, se aseguraba: "ya se ve, el negro cuando no ensucia en la entrada, ensucia en la salida", "no se puede esperar otra cosa de un negro", "es negro de verdad”, etc. Ahora bien, la aparición de oportunidades estables de empleo y de ingresos, así como de ciertas posibilidades de ascensión social, abiertas por el orden social competitivo (principalmente en los últimos 20 años), provocaron que una gran parte de las llamadas "elites de color" o "clases medias de color" se calificara socialmente sin el impulso del paternalismo del blanco y bajo una relativa independencia de esa forma espuria de movilidad social vertical.

Ante ese "nuevo negro", el blanco se veía en una posición confusa y residualmente ambivalente. El "nuevo negro" ya es, en sí mismo, un tipo humano relativamente complicado: tiene una mentalidad más secularizada y urbanizada, no le teme a la libre competencia con el blanco y, sobre todo, pretende "vencer en la vida" a toda costa. Rompe los cordones materiales o morales 
con su "ambiente de origen", negándose a convivir con los "negros pobres", a respetar la solidaridad agreste, que transforma al "negro rico" en una víctima indefensa de sus amigos o parientes "que pasan necesidades", y a mantener un nivel de vida modesto. Rechaza al "negro holgazán", que sería el factor de la eterna degradación del negro por el blanco; y combate los movimientos sociales de cuño racial, afirmando que el "problema no es ése" y que ellos pueden volverse contraproducentes, al despertar ilusiones entre los mismos negros y al fomentar la animosidad del blanco. Absorbe y exagera la mentalidad del blanco, que toma como modelo de sus realizaciones, y pone en práctica un puritanismo ingenuo, pero duro, que lo eximiría de cualquier crítica y lo purificaría de cualquier fuente extrapersonal de degradación moral. Cultiva la delicadeza y la afabilidad como técnicas de suavización de sus actitudes autoafirmantes, pero también como expresión de su manera de ser, de pensar y de medir la grandeza humana. Finalmente, es intransigente ante los blancos que pretenden congelarlo, aplicándoles el estándar tradicionalista de relación racial, pues las anuencias en esa esfera redundarían en la pérdida de los réditos esperados — la conquista del "lugar al que tenga derecho". Considerado en su conjunto, se presenta como el principal agente humano de modernización de las relaciones raciales en la ciudad, pues tiende a una forma activa y constante de rechazo de las manifestaciones tradicionales del prejuicio y de la discriminación racial.

A través de ese tipo humano se ponen de manifiesto tres datos esenciales. En primer lugar, en el momento en que el negro rompe con los estereotipos y con las conveniencias disimuladas, imponiéndose socialmente por sus méritos personales, por su riqueza y por su prestigio, se quiebra inevitablemente una de las polarizaciones que permitía disimular el paralelismo entre "color" y "posición social". Entonces, las líneas de resistencia contra el color se manifiestan con relativa claridad. El prejuicio y la discriminación raciales salen a la superficie sin máscaras. No sólo algunas de las restricciones, que parecían confusamente asociadas a la posición social, deben ser puestas al desnudo en términos 
de color. Además, en situaciones competitivas, el blanco acaba teniendo que apelar, de modo más o menos abierto, a actitudes o comportamientos que se dan de bruces con la tradición del decoro e involucran la apelación al etnocentrismo como recurso de autodefensa. En segundo lugar, algo opuesto también se evidencia con nitidez, aunque de forma aparentemente menos extensa e intensa. Los blancos de propensión realmente tolerante e igualitaria procuran amparar a ese "nuevo negro", resguardándolo de los efectos de la presión indirecta y estimulándolo a proseguir en el camino de sus ambiciones. A pesar de cierto grado variable de ambivalencia de actitudes y de una conciencia deformada de la realidad racial, tales blancos hostilizan el fariseísmo del prejuicio y de la discriminación raciales disimulados, al mismo tiempo que procuran, si bien a veces de manera insatisfactoria, "darle la mano al negro que se lo merece". Por eso, como producto reactivo de la emergencia del "nuevo negro" y por el impacto de su personalidad o de su éxito, algunos círculos de la población blanca también se comprometen de manera más profunda con la modernización de los estándares vigentes de relaciones raciales. En tercer lugar, el medio negro propiamente dicho no reacciona de manera uniforme al éxito del "nuevo negro". Amigos y parientes del mismo nivel social pueden entusiasmarse y ofrecer una base emocional y moral, que les sirve como una especie de caja de resonancia y de fuente de estímulos a las personas en causa. Sin embargo, incluso en el mismo nivel social surgen apreciaciones más o menos malévolas, que minimizan o ridiculizan las pretensiones y las realizaciones del héroe. En los demás círculos de sus relaciones en el medio negro, principalmente debajo del nivel social adquirido, la reacción dominante combina el resentimiento con la satisfacción. El éxito acaba llevando a la ascensión social y ésta se convierte en ruptura. Por eso, los antiguos amigos y parientes se ponen ansiosos; en una extraña reacción amorosa, condenan a aquellos que aman. Empero, por fuera y por encima de las relaciones de carácter personal, el éxito es enfatizado con entusiasmo. Prevalece la idea de que aquello que un negro puede hacer, lo podrá hacer otro también. Se forma, así, un folclor del 
negro en ascensión, que sirve de estímulo a los que aspiran a idénticos objetivos. Sin embargo, los mismos héroes de ese folclor se alejan del "antiguo ambiente", aislándose de su medio de origen y procurando construir laboriosamente el prestigio del "negro recto", de "posición social" y que "es gente". Esta reacción, más o menos típica, divorcia el principal elemento humano del medio negro de las grandes "masas de color", impulsándolo a ignorar la importancia vital de los movimientos que podrían redundar en la aceleración de la democratización de las relaciones raciales.

El tercer problema nos sitúa delante de un enigma. Es imposible prever lo que va a suceder en un futuro lejano en materia de relaciones raciales. Parece probable que las tendencias dominantes lleven, a largo plazo, a la puesta en marcha de una auténtica democracia racial. Sin embargo, en lo inmediato, determinados sucesos que se repiten hacen recelar el desenlace de dichas tendencias. Por lo que vimos, el factor verdaderamente profundo, que produjo algunas modificaciones significativas en el marco histórico-social de las relaciones raciales, viene a ser el desarrollo socioeconómico espontáneo. Ahora bien, evidentemente, hasta la actualidad éste no ha sido suficiente para promover la readaptación del orden racial heredado del pasado a los requisitos de la sociedad de clases. A tal punto esto es verdad, que en muchos círculos sociales, y simultáneamente en los diversos grupos étnicos o nacionales que lo componen, existe una nítida propensión a darles acogida y a poner en práctica antiguos procedimientos prejuzgantes y discriminatorios. Hay quien tiene miedo de perder prestigio social "al aceptar al negro"; hay también quien sólo acepta al negro en la órbita de lo convencional, alejándose de ellos en el área de la verdadera amistad y de la comunión afectiva; hay, finalmente, quien sostiene a toda costa ciertas representaciones arcaicas, y repudia toda posibilidad de incluir al negro en posiciones que involucren el ejercicio del liderazgo y de la dominación. Dejando de lado la cuestión del casamiento interracial, que se topa con resistencias y valoraciones casi ineludibles en la presente coyuntura, datos como aquéllos sugieren el tipo de riesgo que está saliendo a la luz. La concentración racial del ingreso, del prestigio 
social y del poder, las tendencias muy débiles de corrección de los efectos negativos que la misma provoca inexorablemente y las propensiones etnocéntricas y discriminatorias podrán facilitar la absorción gradual del paralelismo entre "color" y "posición social" por el régimen de clases. Parece indudable que esa amenaza existe. Lo peor es que constituye una realidad que sólo puede ser combatida de forma consciente y organizada. Y no parece que, mientras se mantengan las actuales condiciones, tal tipo de reacción social encuentre una viabilidad histórica. A los segmentos blancos de la sociedad no les importa vitalmente el destino de la democracia racial sino la continuidad y el ritmo de expansión del orden social competitivo. Incluso el problema de la democracia en el ámbito político no se plantea como un dilema para esos círculos humanos. Por su parte, los segmentos negros y mulatos de la sociedad no tienen elementos para desencadenar y generalizar el estado de espíritu por una defensa consciente, sistemática y organizada de la democracia racial. Sus sectores pobres, por absoluta falta de los medios apropiados; las llamadas "elites de color", porque no perciben o, si lo hacen, no les parece ventajoso comprometerse ante semejantes objetos que afectan más el futuro de la comunidad que su propio presente. Por consiguiente, la democracia racial está entregada a su destino, sin tener héroes que la defiendan como un valor absoluto. Si la formación y el desarrollo espontáneo de las clases sociales enredaran la desigualdad racial en la desigualdad inherente al orden social competitivo, entonces aquélla estará fatalmente condenada. Continuará siendo un bello mito, como lo es en la actualidad.

Las consideraciones expuestas abarcan apenas algunos aspectos de las manifestaciones y de los efectos del prejuicio y de la discriminación en las relaciones raciales. Pero esos aspectos son suficientes para testimoniar lo que pretendíamos: cómo y por qué el orden social competitivo no absorbió y eliminó, rápida y definitivamente, el patrón de relación racial heredado del pasado señorial y de la esclavitud. Es que los hombres y las sociedades que éstos forman no siempre se modernizan totalmente. A veces, elementos y factores arcaicos continúan existiendo y operando 
más allá de su era histórica, y ejercen influencias negativas en la evolución de la personalidad, de la cultura y de la misma sociedad. Tal parece ser el caso de São Paulo, aunque sea la ciudad más moderna y desarrollada de Brasil. En la esfera de las relaciones raciales, ésta aún se encuentra muy comprometida con el pasado, indecisamente inmersa en un período de transición que se prolonga indefinidamente, como si los negros debieran esperar, para igualarse a los blancos, el advenimiento espontáneo de una Segunda Abolición. ${ }^{3}$

\section{CONCLUSIONES}

Los resultados del presente análisis son obvios. Ellos nos muestran, por un lado, que existe un dilema racial brasileño y que el mismo tiene un carácter estructural. Para enfrentarlo y corregirlo sería necesario cambiar la estructura de la distribución del ingreso, del prestigio social y del poder, estableciendo un mínimo de equidad económica, social y cultural entre "blancos", "negros" y "mulatos". También revelan, por otro lado, que la emergencia y el desarrollo de un orden social competitivo en sí mismos no constituyen garantía de una democratización homogénea del ingreso, del prestigio social y del poder. Las oportunidades que ambos procesos histórico-sociales crean son aprovechadas de forma desigual por las diversas categorías sociales y raciales presentes. La experiencia histórica analizada comprueba que las categorías sociales mejor ubicadas en la estructura económica, social y de poder tienden a monopolizar las ventajas reales y a capitalizar los réditos verdaderamente compensadores del cambio social. En consecuencia, la democratización inherente a los dos procesos tiene dos caras. Una de ellas pone de manifiesto que las grandes masas tienen acceso a ciertos beneficios generales que mejoran su participación en el nivel medio del ingreso, del padrón de vida o de uso del poder político. La otra evidencia que pequeños gru-

Expresión tomada de manifestaciones de intelectuales negros racialmente inconformistas. (N. del E.). 
pos se insertan más o menos privilegiadamente en ese proceso, y mantienen o alcanzan niveles de participación en el ingreso, en el padrón de vida o de uso del poder político que exceden las proporciones medias. En ese sentido, en las etapas de formación y de expansión inicial del orden social competitivo surgen tendencias muy fuertes de agravamiento de las desigualdades económicas, sociales y políticas, en términos de clase, raza o región. La persistencia o la eliminación gradual de esas desigualdades pasan a depender del modo como reaccionan colectivamente las demás categorías sociales a las deformaciones que así se introducen en el estándar de integración, de funcionamiento y evolución del orden social competitivo.

Esos aspectos de la realidad sugieren, querámoslo o no, un cuadro realmente complejo, en el cual se elevan dos problemas centrales. Uno de ellos tiene que ver con los tipos de hombres que "hacen la historia": de qué estratos sociales son extraídos, o qué representan en términos de intereses económicos, sociales o políticos y de identidades ideológicas, nacionales o raciales. En el caso en discusión, tales hombres provenían de categorías sociales muy diversas - representantes de las antiguas elites o sus descendientes, inmigrantes o sus descendientes, elementos seleccionados en poblaciones nacionales migrantes, etc. Todos tenían en común el deseo de enriquecerse, de alcanzar el éxito y de ejercer el poder. Para ellos, los valores ideales del orden social competitivo no mostraban ningún atractivo. Se limitaban a manipularlos como un medio para alcanzar aquellos fines de manera racional, rápida y segura. Por lo tanto, "hicieron historia", pero ignorando a la colectividad y sus problemas humanos. Expurgaron la equidad de su horizonte cultural, y por eso no tenían la perspectiva necesaria para apreciar el drama humano del negro (u otros dramas igualmente desgarradores y dignos de la "acción histórica"). Desde ese ángulo, no sólo se confirma que el negro dejó de contar en el proceso histórico, como si hubiera sido expulsado de la vida social común, sino que se descubre algo peor: la democracia, que provee al mismo tiempo el soporte jurídico-político del orden social competitivo y su única fuente 
de control moral, dejó de inspirar exactamente a aquellos que "hacían la historia".

Otro problema es el de la modernización (y en particular, de sus repercusiones en el plano de las acomodaciones raciales). Es difícil que la modernización pueda alcanzar proporciones equilibradas, igualmente extensas y profundas en todos los niveles de la vida social organizada. Ella acompaña el poder relativo y la vitalidad de los grupos interesados en determinados cambios socioculturales y progresa en virtud de la capacidad que ellos adquieren de concretarlos históricamente. Por eso, la ciudad de São Paulo conoció una rápida transformación de su fisonomía urbana y de su organización económica, mientras que quedó variablemente atada al pasado en otras esferas de las relaciones humanas o del desarrollo institucional. Las relaciones raciales se incluyeron en este último sector y presentaron un índice de estancamiento sorprendente y peligroso. Para que semejante situación se modifique es necesario que con ellas ocurra lo mismo que sucedió con otras esferas de la vida social que se modernizaron rápidamente: los grupos humanos directamente afectados (o interesados) deben tomar conciencia social de esa situación e intentar modificarla de forma organizada. Ello significa, en otras palabras, que es del mismo negro de quien debiera partir la respuesta inicial al desafío impuesto por el dilema racial brasileño. Es él quien debe movilizarse para defender sus objetivos inmediatos —una participación más equitativa en los réditos del orden social competitivo—y para tender a objetivos más lejanos — la puesta en marcha de una auténtica democracia racial en la comunidad. Actuando socialmente en esa dirección, el negro dirigiría a los blancos de los diferentes niveles sociales hacia el alcance de una causa de la cual depende, de manera notoria, el funcionamiento y el desarrollo balanceados del orden social competitivo.

Desde esta perspectiva, se comprende mejor cuánto depende la modernización de las relaciones raciales del grado de racionalidad y de la capacidad de actuación social de ciertos grupos humanos. Bloqueado por la ideología racial elaborada por los blancos y seducido por el afán de "pertenecer al sistema" —es 
decir, de identificarse, en la medida de lo posible, con el mismo blanco-, el negro ha permanecido históricamente neutral, negándose como factor humano de cambios socioculturales que tienen que gravitar, fatalmente, en torno a sus insatisfacciones y aspiraciones histórico-sociales. De esta manera, aparece como la principal víctima de la cadena invisible, resultante de la persistencia del pasado. Se vuelve incapaz de interactuar socialmente, de forma positiva, con las exigencias del presente y deja de afirmarse, en la medida de lo posible, en defensa y en la construcción de su futuro humano.

\section{REFERENCIAS BIBLIOGRÁFICAS ${ }^{4}$}

Bastide, Roger y Florestan Fernandes, Blancos y negros en São Paulo, $2^{a}$ ed., São Paulo, Editora Nacional, 1959 [1ª ed., 1955].

Fernandes, Florestan, La integración del negro a la sociedad de clases, São Paulo, Facultad de Filosofía, Ciencias y Letras de la Universidad de São Paulo, 1964.

4 El lector interesado encontrará, en las dos obras que se referencian, fundamentación empírica e interpretativa para las consideraciones sociológicas expuestas en este trabajo, así como referencias bibliográficas sobre otras publicaciones, pertinentes al tema. (N. del. E.). 